\title{
Nanostructured ceria synthesized by detonation method and its ultraviolet absorption performance
}

\author{
Z. W. $\operatorname{Han}^{1}$, L. F. Xie ${ }^{1}$, Y. C. $\operatorname{Han}^{2}$, O. Q. $\mathrm{Ni}^{1}$, J. Y. Chen ${ }^{1}$ \\ \& Y.C. Xie ${ }^{1}$ \\ ${ }^{1}$ School of Chemical Engineering, \\ Nanjing University of Science and Technology, China \\ ${ }^{2}$ State Key Laboratory of Fire Science, \\ University of Science and Technology of China, China
}

\begin{abstract}
Nanostructured ceria particles have been successfully synthesized by detonation method with emulsion explosives. The effects of mass content of $\mathrm{Ce}\left(\mathrm{NO}_{3}\right)_{3} \cdot 6 \mathrm{H}_{2} \mathrm{O}$ in emulsion explosives on particle size of $\mathrm{CeO}_{2}$ were investigated. X-ray diffraction (XRD) and Transmission Electron Microscope (TEM) were carried out to characterize as-synthesized powders. The ultraviolet absorption performance of nanostructured ceria was tested by ultraviolet spectrophotometer. The results indicated that the mass content of $\mathrm{Ce}\left(\mathrm{NO}_{3}\right)_{3} \cdot 6 \mathrm{H}_{2} \mathrm{O}$ in emulsion explosives affected the particle size of ceria mostly. When the mass content of $\mathrm{Ce}\left(\mathrm{NO}_{3}\right)_{3} \cdot 6 \mathrm{H}_{2} \mathrm{O}$ was $53.2 \%$, the particle size of ceria was even and on the small side. The UV absorption performance of assynthesized nanostructured ceria was excellent, especially for ultraviolet B.

Keywords: nanostructured ceria, detonation synthesis, UV absorption, emulsion explosives, UVB.
\end{abstract}

\section{Introduction}

Excessive exposure to ultraviolet rays (UV) in sunlight induces coloring and deterioration in paper, fabrics and resins. It also causes harmful damage to the human body such as premature aging of skin, skin cancer and cataracts. Among all the wavelengths of UV, UVB $(290-320 \mathrm{~nm})$ is the most harmful. It is the chief 
cause of skin reddening, sunburn and cancer. Nowadays, most of inorganic UVblocking filters are based on titanium dioxide $\left(\mathrm{TiO}_{2}\right)$ and zinc oxide $(\mathrm{ZnO})$. However, a number of reports exist indicating the possibility of brain cells [1], blood lymphocytes [2] and lymphoblastic cells [3] damaged by titania nanoparticles. Moreover, nanoparticles of zinc and titanium oxides possess enormous photocatalytic activity [4], thus inducing the increase in their toxicity upon irradiation. Reactive oxygen species (ROS) forming during photocatalytic processes decompose not only components of cosmetics but even skincells $[5,6]$. It was demonstrated that under $\mathrm{UV}$-irradiation $\mathrm{TiO}_{2}$ and $\mathrm{ZnO}$ nanoparticles being the part of sunscreen cosmetics generate hydroxyl radicals [7, 8] damaging DNA of skin cells [9]. Phototoxicity of titania against fibroblasts has been also confirmed [10].

Ceria $\left(\mathrm{CeO}_{2}\right)$ is one of the today's most promising nanomaterials [11]. Due to the high concentration of oxygen defects in ceria lattice the recombination of free charge carriers (electrons and holes) forming upon UV-irradiation of ceria proceeds very rapidly. It should be also noted that UV-extinction coefficient of ceria is rather high. Therefore this compound is considered as a promising UVfilter in sunscreen cosmetics [12].

Thus this paper focused on a novel method that never has been reported to prepare nanostructured ceria. And the UV absorption performance of nanostructured ceria was tested. We are trying to investigate the application of nanostructured ceria synthesized by detonation method on UV protection.

\section{Experimental}

\subsection{Preparation of emulsion explosives}

As well as the ordinary emulsion explosives which were used for demolishing mines or mountains, this special emulsion explosive for preparing nanostructured ceria was also composed of oxidant, incendiary agents and emulsifiers. In order to obtain nanostructured ceria, cerium nitrate hexahydrate $\left(\mathrm{Ce}\left(\mathrm{NO}_{3}\right)_{3} \cdot 6 \mathrm{H}_{2} \mathrm{O}, \mathrm{AP}\right)$ was regarded as the main oxidant with the mass fraction from $13.3 \%$ to $66.5 \%$. Five kinds of emulsion explosives were prepared with mass fraction of cerium nitrate hexahydrate by $13.3 \%, 26.6 \%, 39.9 \%, 53.2 \%$ and $66.5 \%$ respectively. Ammonium nitrate $\left(\mathrm{NH}_{4} \mathrm{NO}_{3}, \mathrm{AP}\right)$ was regarded as the auxiliary oxidant which played the role of oxygen provider. Compound oil which was a mixture of paraffin wax and machine oil with a certain proportion was regarded as the incendiary agent and SP-80 as the emulsifier. Resin microballs were regarded as the sensitizer. The main components of the emulsion explosives are listed in Table 1.

The aqueous phase (disperse phase) and the oil phase (continuous phase) were mixed with an emulsion machine under a proper oil-bath temperature and some emulsion matrix was obtained. The mixing process lasted for 5 minutes at a mixing speed of $2000 \mathrm{rpm}$ with the emulsion machine. Then the emulsion matrix was sensitized with resin microballs. We got the special emulsion explosives ready for ceria synthesis. 
Figure 1 is a SEM picture of emulsion matrix. In the picture, we can see some droplets of aqueous phase, which look like bulb. The diameters of the droplets were about several micrometers. It was oil phase among the droplets. The aqueous phase and the oil phase composed a stable system called emulsion matrix.

Table 1: $\quad$ Main ingredients of the emulsion explosive.

\begin{tabular}{|c|c|c|c|}
\hline Phase & Chemical name & Chemical formula & $\begin{array}{c}\text { Mass content (wt. } \\
\% \text { ) }\end{array}$ \\
\hline \multirow[t]{2}{*}{ Disperse phase } & $\begin{array}{l}\text { Cerium nitrate } \\
\text { hexahydrate }\end{array}$ & $\mathrm{Ce}\left(\mathrm{NO}_{3}\right)_{3} \cdot 6 \mathrm{H}_{2} \mathrm{O}$ & $13.3-66.5$ \\
\hline & $\begin{array}{l}\text { Ammonium nitrate } \\
\text { water }\end{array}$ & $\begin{array}{c}\mathrm{NH}_{4} \mathrm{NO}_{3} \\
\mathrm{H}_{2} \mathrm{O}\end{array}$ & $\begin{array}{c}25-75 \\
0-10\end{array}$ \\
\hline Continuous phase & $\begin{array}{l}\text { Paraffin wax } \\
\text { Machine oil }\end{array}$ & $\begin{array}{l}\mathrm{C}_{18} \mathrm{H}_{38} \\
\mathrm{C}_{12} \mathrm{H}_{26}\end{array}$ & 6 \\
\hline Emulsifier & SP-80 & $\mathrm{C}_{24} \mathrm{H}_{44} \mathrm{O}_{6}$ & 3 \\
\hline Sensitizer & Resin microballs & $\mathrm{C}_{15} \mathrm{H}_{16} \mathrm{O}_{2}$ & 1 \\
\hline
\end{tabular}

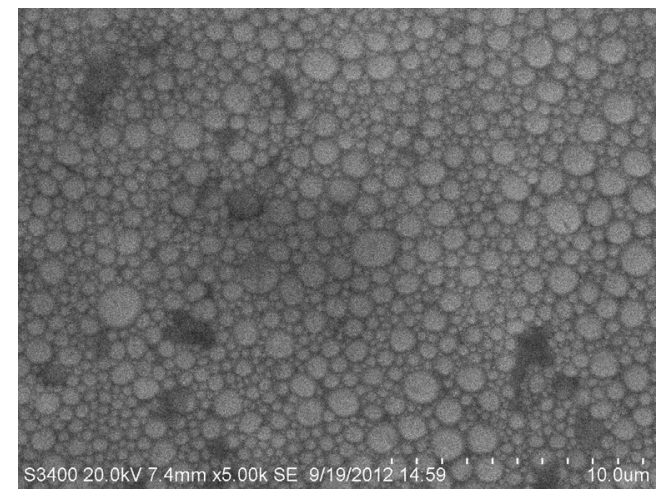

Figure 1: $\quad$ SEM picture of emulsion matrix.

\subsection{Synthesis}

The emulsion explosives were charged in oiled paper tubes which are $30 \mathrm{~mm}$ in inner diameter. Then the experiments were carried out in an explosion vessel. The sketch of explosion vessel is shown in Figure 2. The illustration of each part is noted in the sketch. The vessel consists of two main parts which are the cover plate and the body of explosion vessel. Those two parts are connected by several bolts. In the side wall of the body of explosion vessel, there is a relief valve to release pressure before collecting detonation soot. Because the synthesis process of ceria needs a high pressure and high temperature atmosphere, the explosion vessel must be sealed before detonating. All parts of the vessel must be fabricated precisely. The internal dimensions are $\Phi 200 \times 300 \mathrm{~mm}$. The metal used to fabricate the vessel is strong enough to endure the explosion of emulsion explosives. The designed TNT equivalence of the vessel is $100 \mathrm{~g}$. After the 
detonation of emulsion explosives, some detonation soot was collected from the bottom of the detonation vessel. The soot needed to be filtered and then dried at $80^{\circ} \mathrm{C}$. Some off-white powders were obtained.

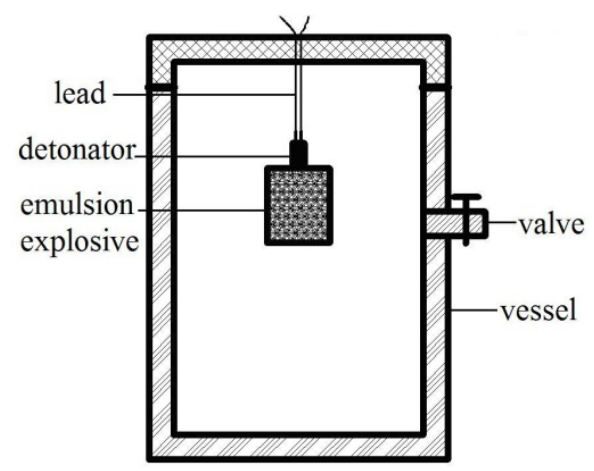

Figure 2: $\quad$ Schematic diagram of explosion vessel.

\subsection{Characterizations}

The powders were assessed with a Bruker D8 X-ray diffractometer (XRD) at room temperature using copper anode as X-ray source $(\lambda=0.154056 \mathrm{~nm})$ at a scanning rate of $4^{\circ} / \mathrm{min}$ in the $2 \theta$ range from $20^{\circ}$ to $70^{\circ}$. The morphology of powders was investigated by using a JEM200 transmission electron microscope (TEM). The ultraviolet absorption performance was detected by an Evolution 220 ultraviolet spectrophotometer. The range of UV wavelength was from $240 \mathrm{~nm}$ to $420 \mathrm{~nm}$.

\section{Results and discussion}

\subsection{Feasibility of detonation synthesis of ceria}

Detonation velocity of emulsion explosives with different mass fraction of cerium nitrate hexahydrate was detected by ion probe method. Before the test was carried out, a pair of probes were inserted into the emulsion explosives charged in oiled paper tubes. The distance between the probes was measured, marked with $L$. Due to the ionization of detonation wave, an equipment could record the time (marked with $\Delta t$ ) when the detonation wave passing by the probes. Then detonation velocity (marked with $D$ ) of the emulsion explosives could be computed according to formula (1).

$$
D=L / \Delta t
$$

The relation curve between detonation velocity and mass content of $\mathrm{Ce}\left(\mathrm{NO}_{3}\right)_{3} \cdot 6 \mathrm{H}_{2} \mathrm{O}$ in emulsion explosives is shown in Figure 3. From Figure 3 we can see that the detonation velocity was decreasing when the mass content of $\mathrm{Ce}\left(\mathrm{NO}_{3}\right)_{3} \cdot 6 \mathrm{H}_{2} \mathrm{O}$ in emulsion explosives increasing. As the fraction was up to 
$66.5 \%$, the emulsion explosives could not be initiated by a detonator because of its high water content and density [13]. Thus it was impossible to use that formula to synthesize ceria by detonation method. In this case, we chose the rest four kinds of emulsion explosives with mass content of $\mathrm{Ce}\left(\mathrm{NO}_{3}\right)_{3} \cdot 6 \mathrm{H}_{2} \mathrm{O} 13.3 \%$, $26.6 \%, 39.9 \%, 53.2 \%$ respectively to synthesize nanostructured ceria.

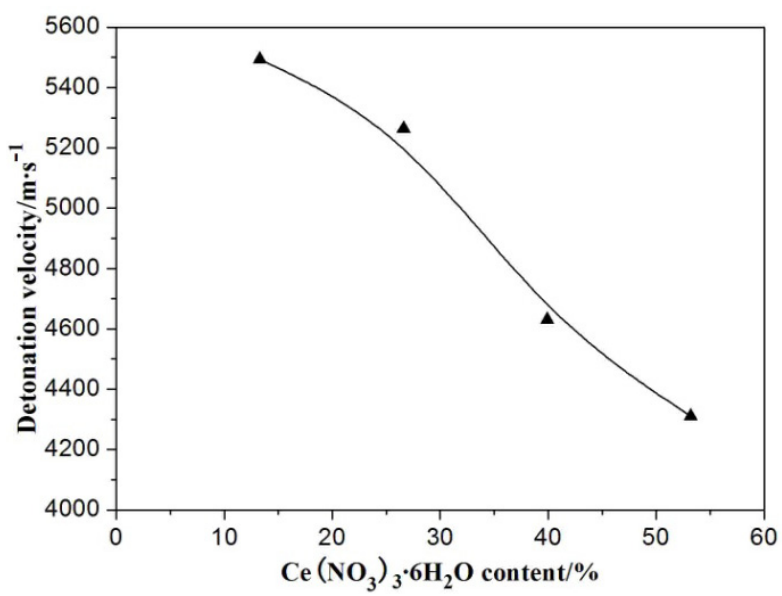

Figure 3: Relationship between detonation velocity and $\mathrm{Ce}\left(\mathrm{NO}_{3}\right)_{3} \cdot 6 \mathrm{H}_{2} \mathrm{O}$ content.

\subsection{Effects of cerium nitrate hexahydrate content in emulsion explosives}

SEM images of emulsion matrix with different formulas are shown in Figure 4. Seen from Figure 4, as a result of the high speed stirring paddles of the emulsion machine, the aqueous phase was dispersed into an oil phase as lots of water solution droplets. The mean diameter of water solution droplets tended to be smaller when the content of $\mathrm{Ce}\left(\mathrm{NO}_{3}\right)_{3} \cdot 6 \mathrm{H}_{2} \mathrm{O}$ increasing. Meanwhile, the dimensional homogeneity of the droplets was better with higher mass content of $\mathrm{Ce}\left(\mathrm{NO}_{3}\right)_{3} \cdot 6 \mathrm{H}_{2} \mathrm{O}$. During the preparation process of different emulsion matrix (emulsion process), we found that the viscosity was growing as the mass content of $\mathrm{Ce}\left(\mathrm{NO}_{3}\right)_{3} \cdot 6 \mathrm{H}_{2} \mathrm{O}$ increasing. Because the operational temperature of emulsion process was above $110^{\circ} \mathrm{C}$ and the mass content of aqueous phase was more than $90 \%$, we have an assumption that the emulsion matrix was Newton fluid. Newton law of viscosity was shown in equation (2).

$$
\tau=\mu \frac{d u}{d y}
$$

where $\tau$ was shearing strength, $\mu$ was viscosity of fluid and $\frac{d u}{d y}$ was velocity gradient. In equation (2), $\frac{d u}{d y}$ was constant due to a specified stirring paddle and 
its corresponding rotation speed. We found that higher mass content of $\mathrm{Ce}\left(\mathrm{NO}_{3}\right)_{3} \cdot 6 \mathrm{H}_{2} \mathrm{O}$ in emulsion matrix generally meant higher viscosity $(\mu)$ of emulsion matrix during the preparation process of emulsion matrix. According to equation (2), we know that shearing strength $(\tau)$ was proportional to viscosity $(\mu)$. So we concluded that it was prone to obtain homogeneous aqueous phase droplets by increasing the viscosity of fluid and shearing strength.
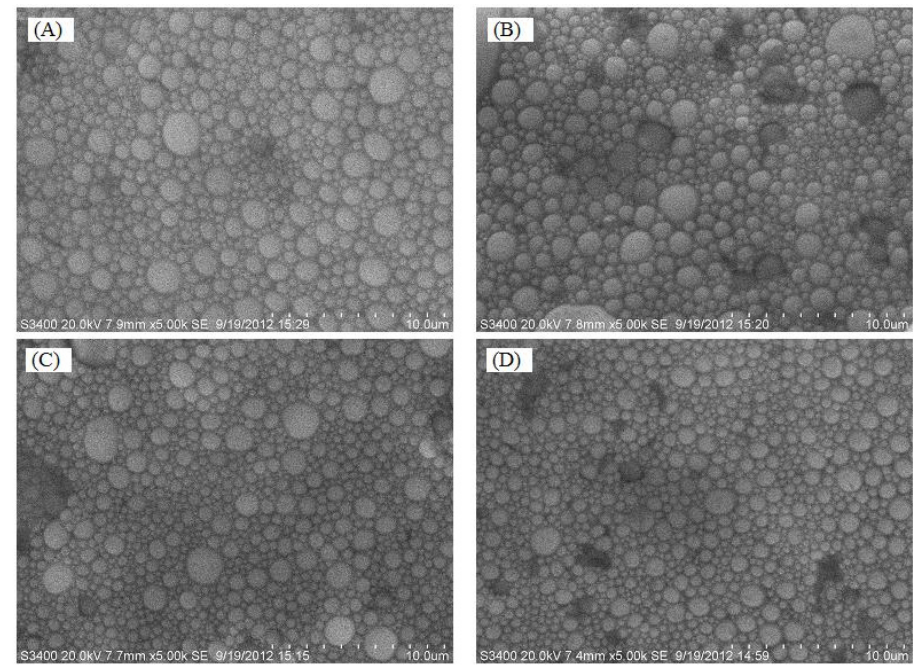

Figure 4: SEM images for emulsion matrix of differfent formulas: (A) $13.3 \% \mathrm{Ce}\left(\mathrm{NO}_{3}\right)_{3} \cdot 6 \mathrm{H}_{2} \mathrm{O}$, (B) $26.6 \% \mathrm{Ce}\left(\mathrm{NO}_{3}\right)_{3} \cdot 6 \mathrm{H}_{2} \mathrm{O}$, (C) $39.9 \%$ $\mathrm{Ce}\left(\mathrm{NO}_{3}\right)_{3} \cdot 6 \mathrm{H}_{2} \mathrm{O}$, (D) $53.2 \% \mathrm{Ce}\left(\mathrm{NO}_{3}\right)_{3} \cdot 6 \mathrm{H}_{2} \mathrm{O}$,

\subsection{Characterization of as-synthesized powder}

The crystal properties of four samples that synthesized by four kinds of formulas were studied by using XRD (X-Ray Diffractometer). Figure 5 is the XRD patterns of four samples. The specification of different samples are shown in Figure 5. Seen from the patterns, we can see that there are six typical diffraction peaks for the four samples, followed successively by $28.59^{\circ}, 33.12^{\circ}, 47.53^{\circ}$, $56.38^{\circ}, 59.14^{\circ}$ and $69.46^{\circ}$. We know that all the four samples were cubic ceria. Actually, all the six diffraction peaks have a right shift about $0.05^{\circ}$. That is because the detonation process of emulsion explosives is so short that the atmosphere with high pressure and high temperature caused by the detonation could only last for about several microseconds or even shorter. During the extremely short time, the crystallites could hardly grow toward preferred orientation, which makes the crystallites have some lattice defects. That is why all four diffraction peaks have a right shift.

The crystallite size of samples was estimated by applying full-width-halfmaximum (FWHM) of characteristic peak (111) to Scherrer equation: 


$$
D=\frac{k \lambda}{\beta \cos \theta}
$$

where $\mathrm{D}$ was the crystallite size, $\mathrm{k}$ was a constant ( 0.89 in this study), $\lambda$ was wavelength of copper target $(0.15406 \mathrm{~nm}$ in this study), $\beta$ was FWHM of characteristic peak (111) and $\theta$ was the diffraction angle for the (111) plane. Seen from the XRD patterns, the FWHM of characteristic peak (111) was increasing as the mass content of $\mathrm{Ce}\left(\mathrm{NO}_{3}\right)_{3} \cdot 6 \mathrm{H}_{2} \mathrm{O}$ in emulsion matrix was growing. According to equation (3), higher FWHM means smaller crystallite size. That means granules prepared by emulsion explosives with higher mass content of $\mathrm{Ce}\left(\mathrm{NO}_{3}\right)_{3} \cdot 6 \mathrm{H}_{2} \mathrm{O}$ were more prone to grow into smaller particles. It was proved by the results of the TEM images shown in Figure 6. The powders obtained from the emulsion explosives with higher mass content of $\mathrm{Ce}\left(\mathrm{NO}_{3}\right)_{3} \cdot 6 \mathrm{H}_{2} \mathrm{O}$ had relatively smaller dimensions (sample (d)).

Seen from Figure 6, sample (d) had relatively uniform particle size. That means an increase in mass content of $\mathrm{Ce}\left(\mathrm{NO}_{3}\right)_{3} \cdot 6 \mathrm{H}_{2} \mathrm{O}$ in emulsion explosions leads to smaller particle size and better dimensional homogeneity of nanostructured ceria. The results can be attributed to the preparation process of emulsion matrix. There was a certain relationship between the dimensional parameters of aqueous phase droplets in emulsion matrix and that of its corresponding ceria particles. Uniform ceria particles with smaller size could be obtained by improving the uniformity of the aqueous phase droplets in emulsion matrix. Base on the results and discussion above, sample (d) was prepared for its ultraviolet absorption performance test.

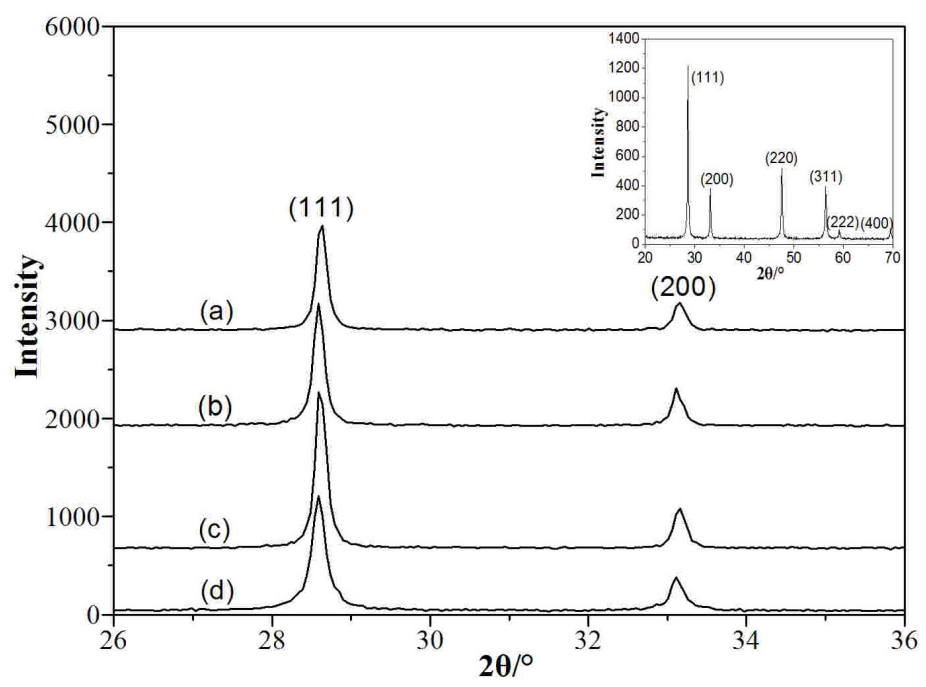

Figure 5: $\mathrm{XRD}$ patterns of as-synthesized powder at different conditions: (a) $13.3 \% \mathrm{Ce}\left(\mathrm{NO}_{3}\right)_{3} \cdot 6 \mathrm{H}_{2} \mathrm{O}$, (b) $26.6 \% \mathrm{Ce}\left(\mathrm{NO}_{3}\right)_{3} \cdot 6 \mathrm{H}_{2} \mathrm{O}$, (c) $39.9 \%$ $\mathrm{Ce}\left(\mathrm{NO}_{3}\right)_{3} \cdot 6 \mathrm{H}_{2} \mathrm{O}$, (d) $53.2 \% \mathrm{Ce}\left(\mathrm{NO}_{3}\right)_{3} \cdot 6 \mathrm{H}_{2} \mathrm{O}$. 

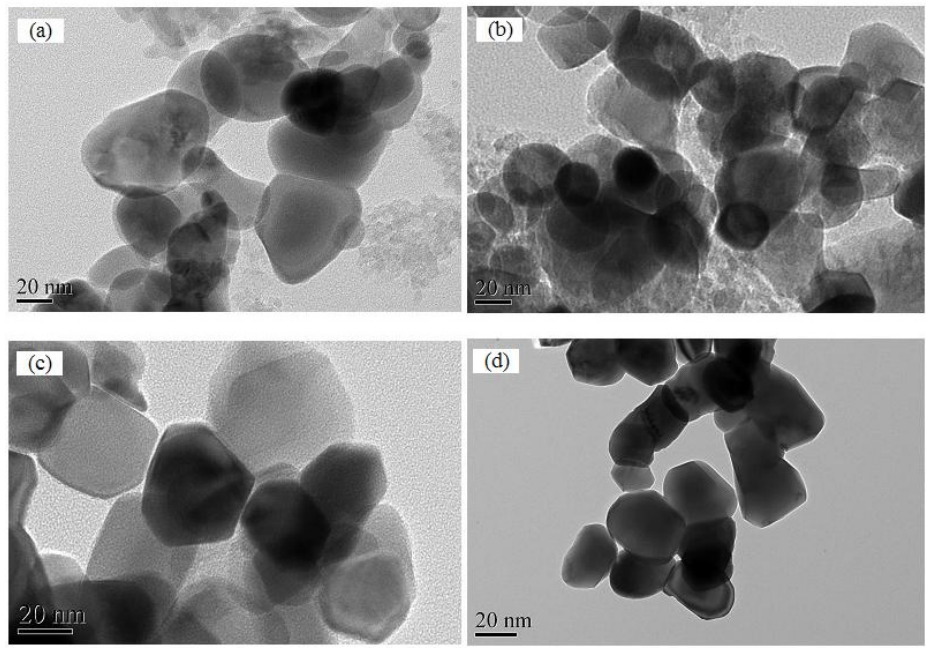

Figure 6: TEM images of nanostructured ceria synthesized at different conditions: (a) $13.3 \% \mathrm{Ce}\left(\mathrm{NO}_{3}\right)_{3} \cdot 6 \mathrm{H}_{2} \mathrm{O}$, (b) $26.6 \% \mathrm{Ce}\left(\mathrm{NO}_{3}\right)_{3} \cdot 6 \mathrm{H}_{2} \mathrm{O}$, (c) $39.9 \% \mathrm{Ce}\left(\mathrm{NO}_{3}\right)_{3} \cdot 6 \mathrm{H}_{2} \mathrm{O}$, (d) $53.2 \% \mathrm{Ce}\left(\mathrm{NO}_{3}\right)_{3} \cdot 6 \mathrm{H}_{2} \mathrm{O}$.

\subsection{UV absorption performance of nanostructured ceria}

The ultraviolet absorption spectrum of sample (d) was shown in Figure 7. Seen from Figure 7, the samples (d) had an excellent performance to filter ultraviolet radiation, whose wavelengths are between $240-360 \mathrm{~nm}$. More precisely, both the ultraviolet type B (UVB, 290-320nm) and the short ultraviolet type A (short UVA, $320-340 \mathrm{~nm}$ ) could be filtered by samples (d). Actually, the ultraviolet

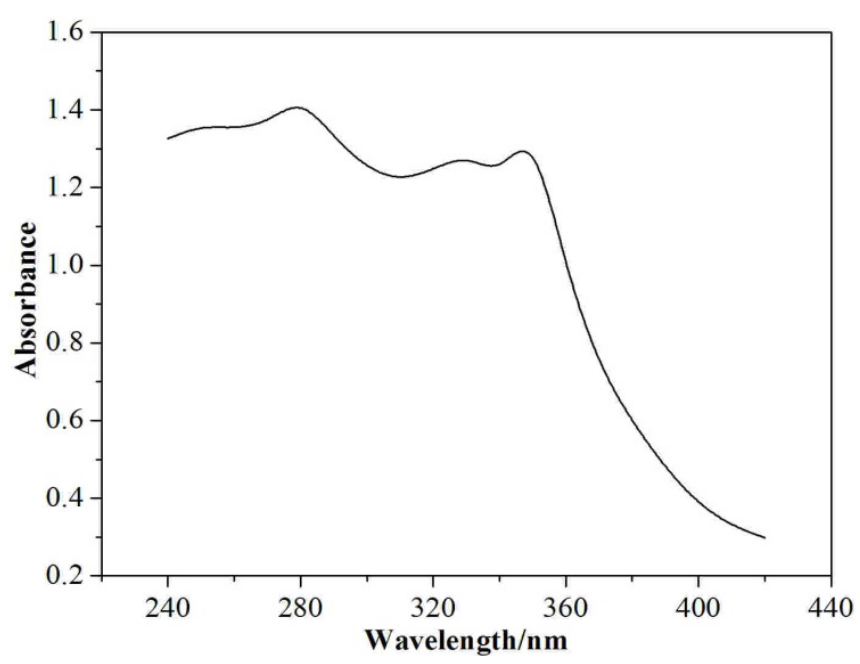

Figure 7: Ultraviolet absorption spectrum of sample (d). 
type A radiation is divided into two domains. One is called short UVA mentioned above. The other is called long UVA, whose wavelengths are from $340 \mathrm{~nm}$ to $400 \mathrm{~nm}$. However, compared with long UVA, short UVA comprises the most energetic and thus it is the most harmful type of UVA radiation. Short UVA is indeed implicated in skin cancers [14]. In this case, sample (d) will be used as potential materials for ultraviolet filtration. It is preferred to be used in sunscreen cosmetic products.

\section{Conclusions}

In the present study we have prepared nanostructured ceria by the detonation method and demonstrated the relationship between the dimensional parameters of nanostructured ceria particles and mass content of $\mathrm{Ce}\left(\mathrm{NO}_{3}\right)_{3} \cdot 6 \mathrm{H}_{2} \mathrm{O}$ in emulsion explosives. From the results, the particle size and its dimensional uniformity of prepared nanostructured ceria are strongly dependent on the mass content of $\mathrm{Ce}\left(\mathrm{NO}_{3}\right)_{3} \cdot 6 \mathrm{H}_{2} \mathrm{O}$ in emulsion explosives. Nanostructured ceria with smaller size and better dimensional uniformity was obtained by increasing the mass content of $\mathrm{Ce}\left(\mathrm{NO}_{3}\right)_{3} \cdot 6 \mathrm{H}_{2} \mathrm{O}$ to $53.2 \%$. This kind of nanostructured ceria had excellent UV filtration performance according to its UV absorption spectrum, especially for harmful UVB. It was a kind of potential material for UV filtration in sunscreen cosmetic products.

\section{Acknowledgement}

The present work was financially supported by Natural Science Foundation of China (Project 11102091).

\section{References}

[1] Long T.C., Tajuba J., Sama P., et al., Nanosize titanium dioxide stimulates reactive oxygen species in brain microglia and damages neurons in vitro. Environmental Health Perspectives, 115(11), pp. 1631-1637, 2007.

[2] Kang S.J., Kim B.M., Lee Y.J., et al., Titanium dioxide nanoparticles trigger p53-mediated damage response in peripheral blood lymphocytes. Environmental Molecular Mutagenesis, 49(5), pp. 399-405, 2008.

[3] Wang J.J., Sanderson B.J. and Wang H., Cyto- and genotoxicity of ultrafine $\mathrm{TiO}_{2}$ particles in cultured human lymphoblastoid cells. Mutation Research, 628(2), pp. 99-106, 2007.

[4] Herrmann J.M., Heterogeneous photocatalysis: fundamentals and applications to the removal of various types of aqueous pollutants. Catalysis Today, 53(1), pp. 115-129, 1999.

[5] Serpone N., Dondi D. and Albini A., Inorganic and organic UV filters: Their role and efficacy in sunscreens and suncare products. Inorganica Chimica Acta, 360(3), pp. 794-802, 2007. 
[6] Brezova V., Gabcova S., Dvoranova D., et al., Reactive oxygen species produced upon photoexcitation of sunscreens containing titanium dioxide (an EPR study), Journal of Photochemistry and Photobiology B: Biology, 79(2), pp. 121-134, 2005.

[7] Uchino T., Tokunaga H., Ando M., et al., Quantitative determination of $\mathrm{OH}$ radical generation and its cytotoxicity induced by $\mathrm{TiO}_{2}$-UVA treatment. Toxicology in Vitro, 16(5), pp. 629-635, 2002.

[8] Sayes C.M., Wahi R., Kurian P.A., et al., Correlating nanoscale titania structure with toxicity: A cytotoxicity and inflammatory response study with human dermal fibroblasts and human lung epithelial cells, Toxicological Sciences, 92(1), pp. 174-185, 2006.

[9] Hidaka H., Kobayashi H., Koike T., et al., DNA damage photoinduced by cosmetic pigments and sunscreen agents under solar exposure and artificial UV illumination. Journal of Oleo Science, 55(5), pp. 249-261, 2006.

[10] Wamer W.G., Yin J.J. and Wei R.R., Oxidative damage to nucleic acids photosensitized by titanium dioxide. Free Radical Biology and Medicine, 23(6), pp. 851-858, 1997.

[11] Zholobak N.M., Ivanov V.K., Shcherbakov A.B., et al., UV-shielding property photocatalytic activity and photocytotoxicity of ceria colloid solutions. Journal of Photochemistry and Photobiology B: Biology, 102(1), pp. 32-38, 2011.

[12] Truffault L., Ta M.T., Devers T., et al., Application of nanostructured Ca doped $\mathrm{CeO}_{2}$ for ultraviolet filtration. Materials Research Bulletin, 45(5), pp. 527-535, 2010.

[13] Yunoshev A.S., Plastinin A.V. and Sil'vestrov V.V., Effect of the density of an emulsion explosive on the reaction zone width. Combustion, Explosion, and Shock Waves, 48(3), pp. 319-327, 2012.

[14] Matsumura Y. and Ananthaswamy H.N., Toxic effects of ultraviolet radiation on the skin. Toxicology and Applied Pharmacology, 195(3), pp. 298-380, 2004. 